\title{
Comparative evaluation of serum CRP levels in chronic and aggressive periodontitis patients before and after non-surgical periodontal therapy-A clinical study
}

\begin{abstract}
Aims and Objectives: C-reactive protein is an acute-phase-reactant primarily produced by the liver in response to infection or trauma. Recent studies have demonstrated a correlation between periodontitis and elevated CRP levels. This study aims to relate the serum-CRP level in chronic and aggressive periodontitis patients, before and after periodontal treatment, with healthy controls.

Materials and Method: A case-control clinical study was conducted with a total of 75 systemically healthy subjects, where 25 subjects were selected in each groups: Group I, Healthy control subjects; Group II, generalized chronic periodontitis patients and Group III, generalized aggressive periodontitis patients. Serum-CRP levels were quantified by using turbidimetric immunoassay at baseline and 3 month post-treatment. Kit used was "TURBILYTE-CRP" (Tulip diagnostics, Goa, India). In treatment phase, patients received single visit nonsurgical periodontal treatment, completed within 24hrs under LAfor GCP \& GAP group.

Results: Mean serum CRP levels were significantly higher in both GCP and GAP group as compared to control group at baseline. On comparing the clinical parameters at 3 month post-treatment for GCP \& GAP group with control group values, mean score of serum CRP levels for GAP group was statistically significant $(P<0.001)$ in comparison to GCP group, which in turn was statistically significant as compared to control group.

Conclusion: The present study indicates a positive correlation between CRP and periodontal disease severity with particular concern in younger individuals, where it could be a possible underlying pathway in the association between periodontal disease and risk for cardiovascular disease in periodontitis patients.
\end{abstract}

Keywords: CRP, aggressive periodontitis, chronic periodontitis, nonsurgical therapy

\section{Introduction:}

Periodontitis defined as "an inflammatory disease of the supporting tissues of the teeth caused by specific microorganisms or groups of specific microorganisms, resulting in progressive destruction of the periodontal ligament and alveolar bone with pocket formation, recession, or both."[1] Various inflammatory cells i.e. polymorphonuclear neutrophils (PMNs), lymphocytes, macrophages \& plasma cells are infiltrated around periodontal tissues representing the alteration in systemic and local immuno-inflammatory response. These inflammatory cells released cytokines i.e. PGE2, IL-1 and TNF- a which cause destruction of periodontal attachment and alveolar bone. As the consequences of systemic immuno-inflammatory response by the monocytes \& other periodontal cells, there is release of cytokines resulting in increased production of Creactive protein.[2]

\begin{tabular}{|l|l|}
\hline \multicolumn{2}{|c|}{ Access this article online } \\
\hline \multirow{2}{*}{$\begin{array}{l}\text { Website: } \\
\text { www.ujds.in }\end{array}$} & Quick Response Code \\
\hline $\begin{array}{l}\text { DOI: } \\
\text { https://doi.org/10.21276/ujds.2020.6.3.2 }\end{array}$ \\
\hline
\end{tabular}

In the periodontal patients, Non-surgical periodontal treatment is carried out to remove microbial biofilm, plaque and calculus which reduces bacterial load and prevents the further disease progression. Outcome of non-surgical periodontal treatment clinically visible as reduce gingival inflammation, \& reduced pocket depth and reduction of clinical attachment loss (CAL) [3,4]

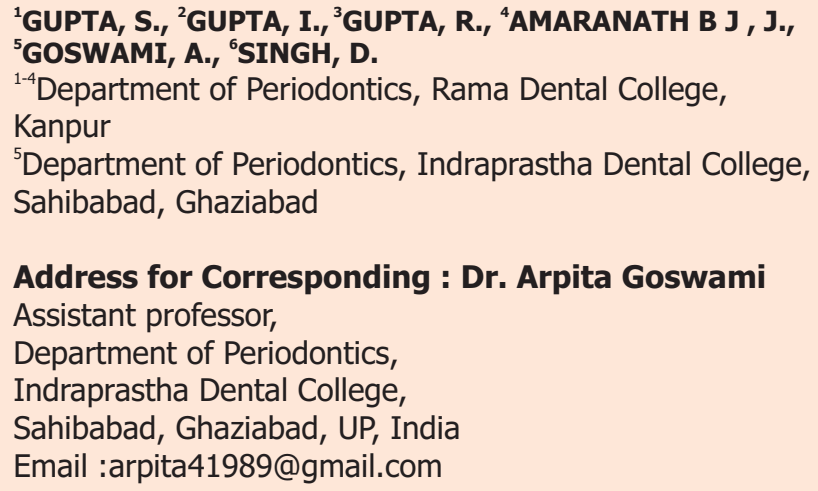
Kanpur

${ }^{5}$ Department of Periodontics, Indraprastha Dental College, Sahibabad, Ghaziabad

Received : 5 Nov. 2020, Published : 31 Dec. 2020 
$\mathrm{C}$ - reactive protein is a nonspecific protein, produced in liver as acute phase reactant in response to various pathological conditions. The level of CRP in healthy individuals is normally i.e. $<0.3 \mathrm{mg} / 1[5,6,7]$ Many studies explained that chronic periodontal disease contributes as a risk factor for atherosclerosis, preterm low birth weight infant and cardiovascular events $[8,9]$ Along with the various risk factors for atherosclerosis, the presence of pathogenic periodontitis associated micro-organisms also play an important role, as they form a niche on the atherosclerotic heart valves. [10-13]

Based on the report of American Heart Association (AHA) and the Center for Diseases Control (CDC), individuals with serum CRP levels $>3.0 \mathrm{mg} / \mathrm{liter}$ are at high risk for future cardiovascular disease.[14] Third National Health and Nutrition Examination survey (NHANES III), observed a positive interlink among serum CRP level, periodontal disease and atherosclerotic complication. Thus, the periodontal disease can be considered as a risk factor for atherosclerosis and cardiovascular events.[15]

According to Tonetti MS et al., biomarkers may play a role in the diagnosis of periodontitis at the early stage and provide an improved assessment in severity of periodontitis. Serum CRP levels not only aid both in staging and grading of periodontitis but also considers the rate of progression of periodontitis. Grade A periodontitis (slow rate of progression) has CRP = $1 \mathrm{mg} / \mathrm{L}$, grade $\mathrm{B}$ (moderate rate of progression) 1 to $3 \mathrm{mg} / \mathrm{L}$ and grade $\mathrm{C}$ (rapid rate of progression) $>3 \mathrm{mg} / \mathrm{L}$ [16]

Many studies.[5,17,18,19,20] have demonstrated levels of serum CRP and their comparison in aggressive and/or chronic periodontitis patients with healthy controls but the studies, correlating the serum CRP levels, pre and post treatment for each group are comparatively few in literature.[21,22] Hence, this study has been carried out with the aim to relate the serum CRP level in untreated cases of chronic and aggressive periodontitis patients before and after non-surgical periodontal treatment with healthy controls.

\section{Materials and Method:}

The subjects for the study were selected from the OPD of Rama Dental College, Hospital and Research center, Kanpur. The informed consent was taken from each patient and the ethical clearance was taken by the ethical committee of Rama Dental College. Sample size was calculated on the basis of maximum and minimum variation in CRP among the three study groups using the formula for comparison of means discussed in 'A. Indrayan, Basic Methods of Medical Research' by putting SD's of CRP as 0.13 of minimum variation and 0.58 for maximum variation in cases and control and a difference of 0.4 considered to be clinically significant.Considering $95 \%$ confidence level, $80 \%$ power of study and $10 \%$ loss to follow up the sample size was calculated to be 25 for each group.

Diagnosis of the periodontal diseases was based on the detailed medical and dental history along with intraoral periapical radiograph of each patient.

\section{Group I: Healthy Control group (C)}

Periodontally healthy subjects, probing depth $(\mathrm{PD})=3 \mathrm{~mm}$ and no evidence of clinical attachment loss

\section{Group II: GCP group:}

Moderate to severe chronic periodontitis patients. Patient's age 30-50yrs, at least 8 teeth with $\mathrm{PD}=3 \mathrm{~mm}, \mathrm{CAL}=3 \mathrm{~mm}$ and presence of alveolar bone loss (ABL) radiographically.

\section{Group III: GAP group:}

25 subjects diagnosed with generalized aggressive periodontitis. Patient's age 20 to 30 years having probing depth (PD) of $=3 \mathrm{~mm}$ and/or CAL $=3$ on 8 or more teeth, at least three of which were not first molars and incisors with varying degree of attachment loss and deposits being inconsistent with periodontal destruction .

\section{Inclusion criteria:}

- Males and Females, having a minimum of 20 teeth.

- Age between 20-50yrs.

- Systemically healthy individuals.

Exclusion criteria:

- Pregnant and lactating females

- Any systemic disease

- Patient under any medication for the past 3 months

- Subjects having any dental treatment in past 6 months

- high blood pressure, sleep disturbances, depression, excessive alcohol use, and smoking recently or in past 10 years

\section{Clinical procedure and study design:}

Phase I

Plaque index [23] (PI) (LOE \& SILNESS), Gingival index [24] (GI) (LOE \&SILNESS), Bleeding index [4] (BI) (AINAMO \& BAY), Calculus index[25] (CI) (NIDR), Probing depth, and Clinical attachment level were recorded at baseline. The probing depth (PD) and clinical attachment 
level (CAL) was evaluated using UNC-15 probe at 6 sites per tooth that is the mesiobuccal, distobuccal, midbuccal, mesiolingual, distolingual, midlingual by single examiner. Blood samples were collected from each participant at baseline for estimation of serum CRP levels.

\section{CRP protein estimation:}

Firstly, the sample of venous blood was taken from anticubital vein. A 24-gauge needle was used for this purpose. The centrifugation of about $3 \mathrm{ml}$ of withdrawn sample was done in a centrifuge machine at $3000 \mathrm{rpm}$ for 10 minutes. This led to separation of serum from blood, which was collected and stored $-200 \mathrm{C}$ followed by estimation of CRP levels, using Turbidimetric immunoassay as per manufacturer instructions [26]

\section{Treatment phase:}

Deplaquing was performed for control group. In group II (GCP) \& group III (GAP), patients received single stage nonsurgical periodontal treatment i.e. scaling and root planing (SRP), completed within 24hrs under local anesthesia. Oral hygiene instruction was reinforced for every patient and they were recalled every month for maintenance phase. In GAP group, along with single stage non-surgical treatment, supportive antibiotic therapy i.e. $500 \mathrm{mg}$ amoxicillin and $400 \mathrm{mg}$ metronidazole were prescribed as TDS dose for a week. Alternative drug, in case of allergy were used which included $250 \mathrm{mg}$ ciprofloxacin and $500 \mathrm{mg}$ metronidazole BD dose for 1 week.

\section{Phase II}

All clinical parameters and serum CRP level were examined again at 3-month post treatment.

\section{Statistical analysis:}

Statistical package for the social sciences (SPSS) version 18 was used for all the statistical analysis. A p-value of $<0.05$ was considered statistically significant. Pearson correlation was used to find the association of periodontal parameters with the changes of serum CRP levels for group II \& III from the baseline.

\section{Results:}

75 subjects (35 male and 40 female), 20-50yrs age participated in the study. The mean ages for healthy, GCP \& GAP group were 26.08, 36.64 and 23.92yrs, respectively.

In intergroup comparison mean score of plaque index (PI), calculus index $(\mathrm{CI})$, gingival index $(\mathrm{GI}) \&$ bleeding index $(\mathrm{BI})$ at base line for GCP group was statistically significant as compared to GAP group. Mean score of serum CRP levels, probing depth (PD) \& clinical attachment level (CAL) for GAP group is statistically significant $(\mathrm{P}<0.001)$ in comparison to GCP which in turn was statistically significant as compared to control group. (TABLE 1)

Table 1: Intergroup Comparison of Various clinical parameters at Baseline for Group II (GCP) and Group III (GAP) with control group

\begin{tabular}{|c|c|c|c|c|c|}
\hline \multirow[t]{2}{*}{ Study Parameters } & Group I(C) & Group II (GCP) & Group III(GAP) & \multirow{2}{*}{$P$-value } & \multirow{2}{*}{ POST-HOC TEST } \\
\hline & Mean \pm SD & Mean \pm SD & Mean \pm SD & & \\
\hline Plaque IndexPI $\dagger$ & $0.80 \pm 0.16$ & $1.49 \pm 0.20$ & $1.28 \pm .09$ & $\mathrm{P}<0.001$ & $\mathrm{GCP}>\mathrm{GAP}>\mathrm{C}$ \\
\hline Calculus IndexCI & $0.65 \pm 0.22$ & $1.61 \pm 0.37$ & $1.51 \pm 0.24$ & $\mathrm{P}<0.001$ & $\mathrm{GCP}>\mathrm{GAP}>\mathrm{C}$ \\
\hline Gingival IndexGI $\dagger$ & $0.69 \pm 0.24$ & $1.66 \pm 0.15$ & $1.48 \pm 0.22$ & $\mathrm{P}<0.001$ & $\mathrm{GCP}>\mathrm{GAP}>\mathrm{C}$ \\
\hline Bleeding indexBI $\dagger$ & $0.45 \pm 0.08$ & $0.82 \pm 0.13$ & $0.72 \pm 0.13$ & $\mathrm{P}<0.001$ & $\mathrm{GCP}>\mathrm{GAP}>\mathrm{C}$ \\
\hline Pocket depthPD $\dagger$ & $1.74 \pm 0.14$ & $6.85 \pm 0.34$ & $6.82 \pm 0.36$ & $\mathrm{P}<0.001$ & GAP, GCP $>$ C \\
\hline Clinical AttachmentLevel AL $\dagger$ & $2.51 \pm 0.25$ & $7.27 \pm 0.47$ & $7.19 \pm 0.23$ & $\mathrm{P}<0.001$ & GAP, GCP $>C$ \\
\hline $\mathrm{C}$ - reactive proteinCRP $\dagger$ & $0.34 \pm 0.09$ & $0.71 \pm 0.24$ & $1,19 \pm 0.64$ & $\mathrm{P}<0.001$ & $\mathrm{GAP}>\mathrm{GCP}>\mathrm{C}$ \\
\hline
\end{tabular}

P-value of $<0.05$ was considered statistically significant.

$\dagger$ ANOVA with post-hoc Games Howell test

‡ANOVA with post-hoc Tukey’s test 
University J Dent Scie 2020; Vol. 6, Issue 3

On correlating the relation between all clinical parameter for control, GCP \& GAP at baseline, PD \& serum CRP levels had moderate positive linear relationship in GAP group and a weak positive relationship for GCP groups. (TABLE2)

Table 2: Comparison of various clinical parameters for GCP \& GAP Group at Baseline With Control Group

\begin{tabular}{|l|c|c|c|c|c|c|c|l|}
\hline \multicolumn{2}{|c|}{} & $\begin{array}{c}\text { Plaque } \\
\text { index } \\
\text { Baseline }\end{array}$ & $\begin{array}{c}\text { Calculus } \\
\text { index } \\
\text { CI }\end{array}$ & $\begin{array}{c}\text { Gingival } \\
\text { index } \\
\text { GI }\end{array}$ & $\begin{array}{c}\text { Bleeding } \\
\text { index } \\
\text { BI }\end{array}$ & $\begin{array}{c}\text { Probing } \\
\text { depth } \\
\text { PD }\end{array}$ & $\begin{array}{l}\text { Clinical } \\
\text { attachment } \\
\text { level (CAL) }\end{array}$ \\
\hline GAP & \multirow{2}{*}{ CRP } & Pearson Correlation & .064 & -.325 & .127 & .152 & .361 & .255 \\
\cline { 3 - 10 } & & p-value & .762 & .113 & .545 & .468 & .077 & .219 \\
\hline GCP & \multirow{2}{*}{ CRP } & Pearson Correlation & .175 & .211 & .291 & .050 & .017 & .174 \\
\cline { 3 - 10 } & & p-value & .402 & .310 & .159 & .814 & .934 & .407 \\
\hline Controls & CRP & Pearson Correlation & .085 & .162 & .168 & -.086 & .220 & .058 \\
\cline { 3 - 9 } & & p-value & .685 & .440 & .422 & .684 & .290 & .782 \\
\hline
\end{tabular}

How to interpret correlation coefficient values when they are significant

- $\quad$ Exactly-1. A perfect negative linear relationship

- $\quad-0.70$. A strong negative linear relationship

- $\quad-0.50$. A moderate negative relationship

- $\quad-0.30$. A weak negative linear relationship

- $\quad 0$. No linear relationship

- $\quad$ +0.30. A weak positive linear relationship

- $\quad+0.50$. A moderate positive relationship

- $\quad+0.70$. A strong positive linear relationship

- Exactly+1. A perfect positive linear relationship

Table 3: Intragroup Comparison of Various Clinical Parameters from Baseline to 3 Month Post-treatment for Group II (GCP)

\begin{tabular}{|l|c|c|c|}
\hline \multirow{2}{*}{\multicolumn{1}{|c|}{ Study Parameters }} & Baseline & After 3 month & \multirow{2}{*}{ P -value } \\
\cline { 2 - 3 } & Mean \pm SD & Mean \pm SD & \\
\hline Plaque Index PI & $1.49 \pm 0.20$ & $0.61 \pm 0.14$ & $\mathrm{P}<0.001$ \\
\hline Calculus Index CI & $1.61 \pm 0.37$ & $0.14 \pm .04$ & $\mathrm{P}<0.001$ \\
\hline Gingival Index GI & $1.66 \pm 0.15$ & $0.61 \pm 0.09$ & $\mathrm{P}<0.001$ \\
\hline Bleeding index BI & $0.82 \pm 0.13$ & $0.35 \pm 0.10$ & $\mathrm{P}<0.001$ \\
\hline Pocket depth PD & $6.85 \pm 0.34$ & $5.90 \pm 0.55$ & $\mathrm{P}<0.001$ \\
\hline Clinical attachment level CAL & $7.27 \pm 0.47$ & $5.92 \pm 0.87$ & $\mathrm{P}<0.001$ \\
\hline C- reactive protein CRP & $0.71 \pm 0.24$ & $0.58 \pm 0.11$ & $\mathrm{P}<0.001$ \\
\hline
\end{tabular}

P-value of $<0.05$ was considered statistically significant.
After 3 month post treatment all clinical parameter improved \& statistically significant, In Intra-group comparison for GCP group, mean score of serum CRP levels at baseline $(0.71 \pm 0.24)$ was statistically significant $(\mathrm{P}<0.001)$ in comparison to the mean score at 3 months post treatment $(0.58 \pm 0.11)$ (TABLE 4$)$ and for GAP group base line mean score of serum CRP levels $(1.19 \pm 0.41)$ was also statistically significant $(\mathrm{P}<0.001)$ as compared to 3 months. $(0.90 \pm 0.41)$.

On comparing the values of all the clinical parameters at 3 months post treatment for GCP \& GAP group with control values, Mean score of serum CRP levels for GAP group was statistically significant $(\mathrm{P}<0.001)$ in comparison to GCP group which in turn was statistically significant as compared to control group at the base line.

Table 4: Intragroup Comparison of Various Clinical Parameters from Baseline to 3 Month post treatment for Group III (GAP)

\begin{tabular}{|l|c|c|c|}
\hline Study parameters & Baseline & After 3 month & \multirow{2}{*}{ P -value } \\
\cline { 2 - 3 } & Mean \pm SD & Mean \pm SD & \\
\hline Plaque Index & $1.28 \pm .09$ & $0.52 \pm 0.11$ & $\mathrm{P}<0.001$ \\
\hline Calculus Index & $1.51 \pm 0.24$ & $0.14 \pm .04$ & $\mathrm{P}<0.001$ \\
\hline Gingival Index & $1.48 \pm 0.22$ & $0.53 \pm 0.13$ & $\mathrm{P}<0.001$ \\
\hline Bleeding index & $0.72 \pm 0.13$ & $0.27 \pm 0.09$ & $\mathrm{P}<0.001$ \\
\hline Pocket depth & $6.82 \pm 0.36$ & $6.36 \pm 0.43$ & $\mathrm{P}<0.001$ \\
\hline Clinical attachment level & $7.19 \pm 0.23$ & $6.88 \pm 0.25$ & $\mathrm{P}<0.001$ \\
\hline C- reactive protein & $1.19 \pm 0.64$ & $0.90 \pm 0.41$ & $\mathrm{P}<0.001$ \\
\hline
\end{tabular}




\section{Discussion:}

The present study was conducted to evaluate the serum CRP level in chronic and aggressive periodontal patients before and after non-surgical periodontal therapy. The result of this study showed an increase in serum CRP levels in GCP and GAP subjects as compared to the healthy controls, which approves the results of the previous studies. [20,27,28]

Salzberget al. [5] found that serum CRP levels were elevated in both, generalized and localized aggressive periodontitis patients as comparison with non-periodontitis group. Thus, it was clear that even the mild disease progression of aggressive periodontitis would add up to the raised serum CRP levels due to the aggressive nature of disease. In present study, a positive linear relationship for serum CRP levels to PD \& CAL was observed in both GCP and GAP groups. Similar findings have also been reported in the previous studies.[29-33] Subgingival microflora, associated with periodontal disease affect systemic host immune response and stimulate the production of cytokines and inflammatory reaction, resulting in increased production of acute phase reactant i.e. C-reactive protein.

Slade et al.[15] reported a dose- response relationship between CRP and extent of periodontitis. Similarly, in the current study the serum CRP levels were higher in severe cases of periodontitis as compared to the mild or moderate ones. Thus, contributing as a risk factor for various systemic inflammatory diseases such as atherosclerosis etc.

In the present study, the GCP \& GAP group showed a significant improvement in various clinical parameters at 3-month post treatment along with decrease in serum CRP values. These findings were confirmed in the previous studies [22, 34, 35] which showed a significant reduction in serum CRP levels after periodontal treatment. Therefore, it could be explained that the periodontal treatment lowers the serum CRP levels which further reduces systemic and local inflammation.

Although, in current study, no antibiotic or anti-inflammatory drug therapy was prescribed for GCP group patients but still, post treatment serum CRP level statistically decreased as stated in other study, which proves itself the importance of nonsurgical treatment in periodontal disease $[34,35]$

Sometimes only non-surgical periodontal treatment may not be sufficient in moderate to severe cases of periodontitis due to extensive attachment loss which may need further surgical approach to maintain periodontal health at those sites. Although, we employed single stage non-surgical treatment in our study, but repeated scaling \& root planing along with supportive and maintenance therapy may bring out more efficient outcome from non-surgical therapy itself. Therefore, more controlled and long-term studies are required in future to depict the association of serum CRP levels with disease progression and its usefulness in early detection and diagnosis. Small sample size and short duration are major limitation of this study. Moreover, subjects with any undiagnosed systemic risk factor might have been included in the study that could influence the results.

\section{Conclusion:}

Results of current study summarized that periodontal disease have a positive association with increased serum CRP levels and periodontal treatment helps to reduce the serum levels of C-reactive protein and minimize local and systemic bacterial load. Thus, these findings suggest the possible relationship among serum CRP levels, periodontitis and risk factor for cardiovascular events, systemic inflammation and atherosclerotic lesion and also predicts that the non-surgical therapy in periodontitis would be highly helpful for reduction of serum CRP, thus reducing systemic risks.

\section{References:}

1. Armitage GC. Ann Periodontology. 1999 Dec;4(1):1-6.

2. Smitha CN, Soni S, BASU SK. Role of C- reactive protein and periodontal disease in systemic health: A review. Journal of Advanced Dental Research. 2011;2(1):1-6.

3. Perry DA, Schmid MO, Takei HN. Phase I periodontal therapy. In Newman MG, Takei H, Klokkevoid P, Carranza FA editors. Carranza's Clinical Periodontology. 10th ed. Saunders, Elsevier, St Louis, Missouri: 2006.p. 722-27.

4. Kanaparthy A, Kanaparthy R, Niranjan. Evaluation of serum C-reactive protein levels in subjects with aggressive and chronic periodontitis and comparison with healthy controls. Dental research journal. 2012;9(3):261-5.

5. Salzberg $\mathrm{TN}$ et al. C reactive protein in patients with aggressive periodontitis. J Periodontol. 2006;77: 933-9.

6. D'Aiuto F, Ready D, Tonetti MS. Periodontal disease and C-reactive protein-associated cardiovascular risk. J Periodontal Res 2004;39:236-41. 
7. Thakare KS, Deo V, Bhongade ML. Evaluation of the Creactive protein serum levels in periodontitis patients with or without atherosclerosis. Indian J Dent Res 2010;21:326-9.

8. Williams RC, Offenbacher S. Periodontal medicine: The emergence of a new branch of periodontology. Periodontol 2000 2000;23:9-12.

9. Radafshar $\mathrm{G}$ et al. Association between Periodontal Disease and Elevated $\mathrm{C}$ - reactive protein in Acute Myocardial Infarction Patients. Journal of Dentistry, Tehran University of Medical Sciences. 2006; 3(3):127-4.

10. Ross R. Atherosclerosis - An inflammatory disease. N Engl J Med 1999;340:115-26.

11. Pejcic A, Kesic L, Milasin J. Association between periodontopathogens and CRP levels in patients with periodontitis in Serbia. J Dent Res Dent Clin Dent Prospects 2011;5:10-6.

12. Page RC. The role of systemic inflammatory mediators in the pathogenesis of periodontal disease. J Periodontol Res. 1991; 26:230-42.

13. Senthil N, Vandana KL, Sangeeta D. A study to qualitatively evaluate the serum levels of C-reactive protein (CRP) in various inflammatory periodontal diseases. J Indian Soc Periodontol2001;5:27-30.

14. Kluft C, de Maat MP. Determination of the habitual low blood level of C-reactive protein in individuals. Ital Heart J. 2001; 2:172-180.

15. Slade GD, Offenbacher S, Beck JD, Heiss G, Pankow JS. Acute-phase inflammatory response to periodontal disease in the US population. J Dent Res. 2000;79(1):49-57.

16. Tonetti MS, Greenwell H, Kornman KS. Staging and grading of periodontitis: Framework and proposal of a new classification and case definition. J Periodontol. 2018;89(Suppl 1):S159-S172.

17. Ionnaidu E et al. Effect of periodontal treatment on serum $\mathrm{C}$ reactive protein: A systematic review and metaanalysis. J periodontal. 2006;77:1635-42.

18. J. Mysak et al. C-reactive protein in patients with aggressive periodontitis. Journal of Dental Sciences (2017) 12, 368-374.

19. Bansal T, Pandey A, Deepa D, Asthana AK. C-reactive protein (CRP) and its association with periodontal disease: a brief review. Journal of Clinical and Diagnostic Research. 2014;8(70):21-4.

20. Goyal L, Bey A, Gupta ND, Sharma VK. Comparative evaluation of serum $\mathrm{C}$-reactive protein levels in chronic and aggressive periodontitis patients and association with periodontal disease severity. Contemporary Clinical Dentistry. 2014;5(4):484-8.

21. Tatjana Ramich et al. Inflammatory serum markers up to 5 years after comprehensive periodontal therapy of aggressive and chronic periodontitis. Clinical Oral Investigations (2018) 22:3079-3089.

22. Eickholz $\mathrm{P}$ et al. Non-surgical periodontal therapy decreases serum elastase levels in aggressive but not in chronic periodontitis. J Clin Periodontol 2013; 40: 327-333.

23. Silness J, Loe H. Periodontal disease in pregnancy. II. Correlation between oral hygiene and periodontal condtion. ActaOdontolScand, 1964;22:121-35.

24. LÖe H. The Gingival Index, the Plaque Index and the Retention Index Systems. J periodontal. 1967;38(6):610-6.

25. Peter S, Essentials of preventive community dentistry. 3rded. NewDelhi: Arya publication;2008.

26. http://www.tulipgroup.com/Tulip_New/html/pack _inserts/Turbilyte_CRP.pdf.

27. Desvarieux $M$ et al. Periodontal microbiota and carotid intima-media thickness: the Oral Infections and Vascular Disease Epidemiology Study (INVEST). Circulation. 2005;111:576-82.

28. Iwamoto Y, Nishimura F, Soga Y. Antimicrobial periodontal treatment decreases serum C-reactive protein, tumor necrosis factor-alpha, but not adiponectin levels in patients with chronic periodontitis. J Periodontol. 2003;74:1231-6.

29. Offenbacher S, Beck JD, Moss K. Results from the Periodontitis and Vascular Events (PAVE) Study: a pilot multicentered, randomized, controlled trial to study effects of periodontal therapy in a secondary prevention model of cardiovascular disease. J Periodontol. 2009;80:190-201.

30. Chopra R, Patil SR, Kalburgi NB. Association between alveolar bone loss and serum C-reactive protein levels in aggressive and chronic periodontitis patients. J IndSocPeriodontol. 2012;16(1):28-1.

31. Pejcic Ana et al. The Markers of Systemic Inflammation in Patients with Chronic Periodontitis: Leukocytes, C reactive protein and Fibrinogen. World Journal of Preventive Medicine. 2013;1(3):43-49.

32. Glurich I, Grossi S, Albini B, Ho A, Shah R, Zeid M, et al. Systemic inflammation in cardiovascular and periodontal disease: Comparative study. Clin Diagn Lab Immunol 2002;9:425-32. 
University J Dent Scie 2020; Vol. 6, Issue 3

33. Noack B, Genco RJ, Trevisan M. Periodontal infections contribute toelevated systemic C-reactive level. J Periodontol. 2001;2:172-80.

34. Kamil W, Habashneh W, Khader Y, Bayati L, Taani D. Effects of nonsurgical periodontal therapy on C-reactive protein and serum lipids in Jordanian adults with advanced periodontitis. J peridontol research. 2011;45:616-21.

35. Mattila K, Vesanen M, Valtonen V. Effect of treating periodontitis on C-reactive protein levels:A pilot study. BMC Infect Dis. 2002;2:30-6. 